\title{
A Two-Stage Heuristic Model For Intermediate- Run Sectorial Petroleum Allocation In A Multi-Regional Setting
}

\author{
David Mulkey and James Hite*
}

\section{INTRODUCTION}

\section{Background}

Most petroleum analysts agree that the United States faces a generation of potential shortages of petroleum products. Careful conservation practices and political stability in the Middle East could mean that no shortages of consequence will actually occur. Moreover, even if actual shortages do develop, they could be of small enough magnitude to be easily resolved through market mechanisms without causing unacceptable political consequences. Yet the embargo on shipment of oil to the United States imposed by the Middle East nations in the winter of 1973-74 demonstrated the potential for shortages of a severe nature. A renewal of such a boycott would probably precipitate a return to the bureaucratic allocation policy of the 1973-74 boycott. It would be sheer folly to fail to develop contingency plans for such an emergency.

In this paper we will outline a two-stage, heuristic model for bureaucratic allocation procedures. Our basic assumptions are: 1) the primary responsibility for such allocation will be vested with the various states, and 2) each state will attempt to allocate limited petroleum stocks so as to provide maximum protection to its economic base. We will further assume that a usable interregional input-output model of the U.S. economy is available and that each state has information on the size of the petroleum stocks available for allocation. ${ }^{1}$

\section{Nature of the Problem}

The nature of the problem facing bureaucrats charged with allocation of petroleum stocks is a function of the time frame within which the allocations must be made. In the very short-run (90-120 days), non-petroleum inputs are unlikely to be a constraint on production since it can be reasonably assumed that inventory stocks can be drawn upon to sustain output. Indeed, even petroleum stocks may not be an effective constraint until oil already in the pipeline at the time of the imposition of the boycott is drawn off. In the very long-run, struc-

\footnotetext{
*Visiting Instructor and Associate Professor, Department of Agricultural Economics and Rural Sociology, Clemson University, Clemson, South Carolina. The support of the Federal Energy Agency and the South Carolina Energy Management Council is acknowledged.

1For an example of such a model, see Polenske (8). A rationale for use of input-output models in analysis of energy problems is contained in Carter (1) and an example of an application is a recent paper by Mulkey and Hite (7).
} 
tural adjustments to petroleum scarcities, involving development of new, petroleum-conserving technology, are likely to so drastically alter input-output coefficients as to make any forecasts of petroleum requirements little more than conjecture. ${ }^{2}$ Hence, the short-run allocation problem is rather straightforward: Allocation of scarce petroleum stocks to maximize an objective function subject only to such non-petroleum constraints as are needed to prevent certain sectors of the economy from receiving more petroleum than they can use, given existing plant capacities. The long-run problem is one of monitoring structural changes to maintain up-to-date input-output coefficients. These problems are by no means trival, but they are far easier to deal with than problems associated with the intermediate-run.

In the intermediate-run, both petroleum and non-petroleum inputs are likely to be effective constraints on production. After three or four months of an embargo which seriously curtails petroleum stocks, supplies of vital non-petroleum inputs may dwindle as inventories cannot be replenished due to cut-backs in the production of intermediate goods. Interindustry flows of goods-both intra- and interregional-are likely to be interrupted and there is the potential that petroleum allocations to some economic sectors will go unused because industries cannot obtain necessary non-petroleum inputs.

The problem can perhaps best be understood by reference to Figure 1. For purposes of simplification, assume a closed economy divided into two regions (or states). Further assume that this is a two-product economy characterized by linear production functions requiring inputs in constant proportions. Region $\mathrm{A}$ is specialized in production of $\mathrm{X}$ and Region $\mathrm{B}$ in production of $\mathrm{Y}$. Furthermore, assume that $\mathrm{X}$ is a vital input for production of $\mathrm{Y}$ and $\mathrm{Y}$ a vital input for production of $\mathrm{X}$. Thus, Region A must have imports of $\mathrm{Y}$ from Region $\mathrm{B}$ and Region $\mathrm{B}$ must have imports of $\mathrm{X}$ from Region $\mathrm{A}$.

In Figure 1, we assume that both regions determine initial optimum allocations of petroleum to industries $\mathrm{X}$ and $\mathrm{Y}$, respectively, based on independent linear programming solutions in which imports from the other region are not considered as constraints. Such initial allocations are appropriate in the front-end period of an embargo. These initial allocations result in providing $\mathrm{OF}_{\mathrm{a}}$ amount of petroleum to $\mathrm{X}$ and $\mathrm{OF}_{\mathrm{b}}$ amount of petroleum to $\mathrm{Y}$. Hence, early in the embargo period, production of $\mathrm{X}$ is $\mathrm{OX}_{1}$ and production of $\mathrm{Y}$ is $\mathrm{OY}_{1}$. At the $\mathrm{OX}_{1}$ level of production, Region A will be able to export to Region $\mathrm{B}$ an amount of $\mathrm{X}$ equal to $\mathrm{OX}_{\mathrm{a}}$ which will be available to $\mathrm{Y}$ as inputs for production in period two. Likewise, at the $\mathrm{OY}_{1}$ level of production, Region $\mathrm{B}$ will be able to export to Region $\mathrm{A}$ an amount of $\mathrm{Y}$ equal to $\mathrm{OY}_{\mathrm{b}}$, which will be available to $\mathrm{X}$ as inputs in production period two.

However, in production period two the intermediate-run problems begin to arise. The $\mathrm{OX}_{\mathrm{a}}$ amount of imports available to Region $\mathrm{B}$ from Region $\mathrm{A}$ is only 

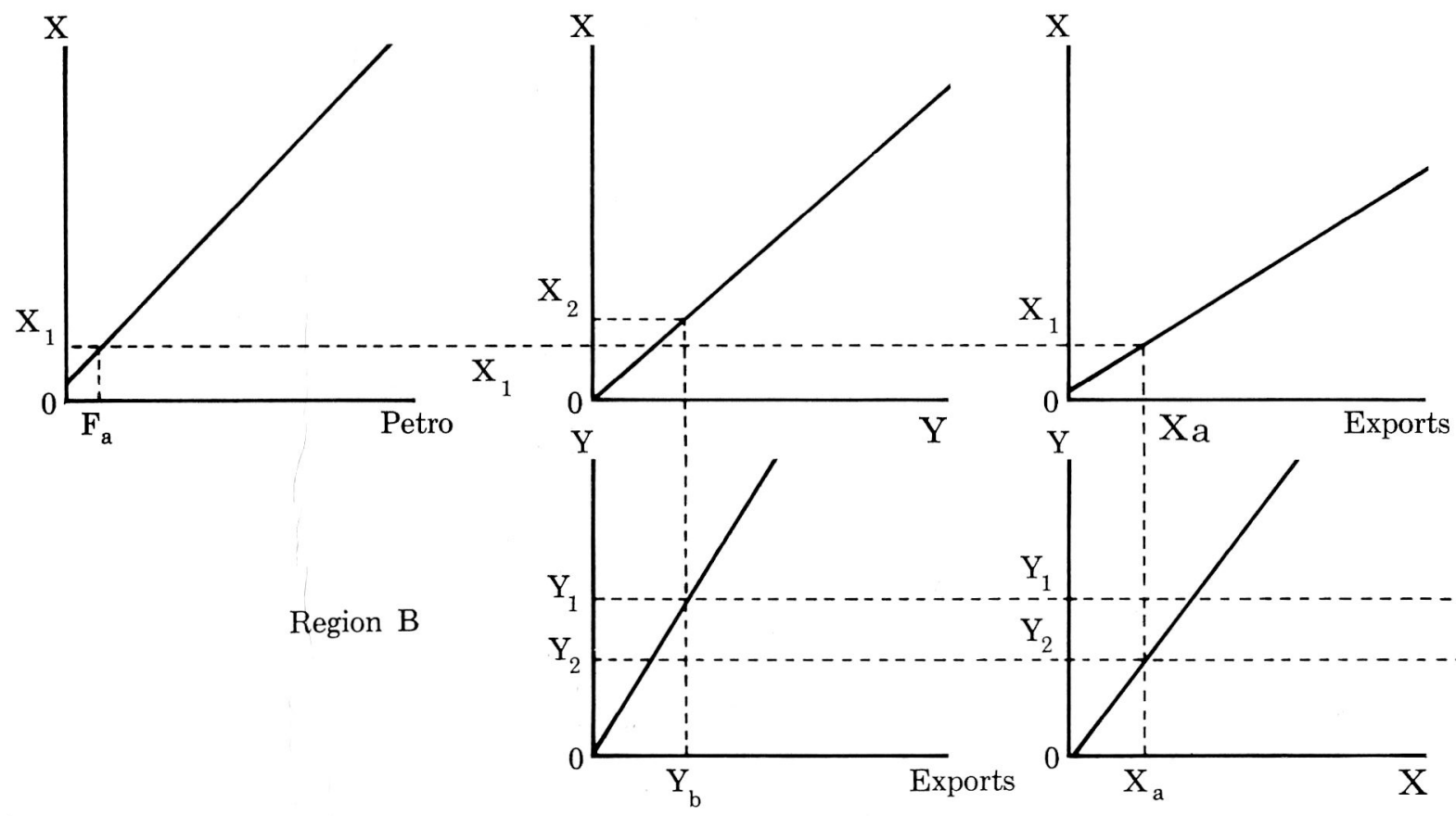

Region A

Region B

Figure 1. Two-region, two-product model of production in petroleum embargo conditions 
sufficient to sustain production of $\mathrm{Y}$ at level $\mathrm{OY}_{2}$, a level somewhat below that which continued allocation of $\mathrm{OF}_{\mathrm{b}}$ amount of petroleum will support. Conversely, the $\mathrm{OY}_{\mathrm{b}}$ amount of imports available to Region A from Region $\mathrm{B}$ will sustain production of $\mathrm{X}$ at a level equal to $\mathrm{OX}_{2}$, a level somewhat greater than continued allocation of $\mathrm{OF}_{2}$ amount of petroleum will support. Since production levels in period two are constrained by the most limiting factor, production will be $\mathrm{OX}_{1}$ and $\mathrm{OY}_{2}$, respectively, in Regions $\mathrm{A}$ and $\mathrm{B}$. Hence, $\mathrm{Y}$ will have $\mathrm{OF}_{\mathrm{b}}$ amount of petroleum available but will be able to utilize only $\mathrm{OF}_{\mathrm{b}}^{\prime}$ amount of petroleum, and $\mathrm{OF}_{\mathrm{b}}-\mathrm{OF}_{\mathrm{b}}^{\prime}$ amount of petroleum which would have been used to support production will be unused. Except for the "waste" of petroleum, the two-region system is in equilibrium in period two. If there is no feedback of information relative to excess petroleum being allocated to $\mathrm{Y}$, petroleum will continue to be allocated to that industry in excess of its ability to use it, given availability of inputs of $\mathrm{X}$, and overall production will continue at levels below that which total available petroleum stocks would support. The problem is one of classic suboptimization.

\section{Alternative Solutions}

There are several alternative solutions to the intermediate-run problem described above. The most straightforward is simply to discard bureaucratic allocation in favor of the market. ${ }^{3}$ Such a solution not only violates one of our initial basic assumptions, it also produces a potential "second-best" situation unless perfectly competitive markets exist throughout the economy. ${ }^{4}$ Another possibility is to abandon regional, or state, bureaucratic allocation in favor of federal allocation. The political barriers to this approach probably render it unrealistic which is why we initially assumed that primary responsibility for allocation would be at the state level. The alternative we have chosen to explore in this paper is a twostage allocation process involving cooperative state-federal efforts. The model which we develop is heuristic in the sense that it facilities a systematic search for improved allocations but does not guarantee a global optimum as a final result. ${ }^{5}$

\section{The MODEL}

\section{General Format}

The model which we propose is based on an iterative scheme involving two levels of decision-making: Regional (or state) and federal. The model is iterated as many times as necessary until no improvement in the allocations is observed in reference to the objective function, or functions. While explication of the model

3 See (3) and (5).

${ }_{4}^{4}$ See (4).

5 For more on the rationale of such an approach, see (2). 
is couched in terms of real-time application, it can, in practice, be utilized as a simulation model so that the practical application of the final solution can commence with initial imposition of an embargo. Hence, the model is intended as a planning tool for forecasting intermediate-run sectorial petroleum allocations in a multi-regional setting.

\section{Source of Coefficients}

We assume an $h$ region interregional input-output matrix of a closed economy of the form schematically represented in Figure 2. Such a matrix includes $h$ regional input-output sub-matrices $\left[k_{X}\right]$ and $h^{2}-h$ interregional trade-flow sub-matrices $[\mathrm{kl} B]$, each of the order $\mathrm{n} \times \mathrm{n}$. Then:

$$
{ }^{\mathrm{kl}} \mathrm{b}_{\mathrm{ijt}} \quad \boldsymbol{\epsilon} \quad\left\{\left[{ }^{\mathrm{kl}} \mathrm{B}_{\mathrm{t}}\right]\right\}
$$

and

$$
{ }^{\mathrm{lk}} \mathrm{b}_{\mathrm{ijt}} \quad \epsilon \quad\left\{\left[{ }^{\mathrm{lk}} \mathrm{B}_{\mathrm{t}}\right]\right\}
$$

where $\left[{ }^{k l} B_{t}\right]$ is an $n \times n$ sub-matrix of interregional trade flows from the $j^{\text {th }}$ sector in the $\mathrm{k}^{\text {th }}$ region to the $\mathrm{i}^{\text {th }}$ sector in the $\mathrm{l}^{\text {th }}$ region in period $t$, and

$\left[{ }^{\mathrm{lk}} B_{t}\right]$ is an $\mathrm{n} \times \mathrm{n}$ sub-matrix of interregional trade flows from the $\mathrm{j}^{\text {th }}$ sector in the $\mathrm{l}^{\text {th }}$ region to the $\mathrm{i}^{\text {th }}$ sector in the $\mathrm{k}^{\text {th }}$ region in period $t$.

Also: $\left[\mathrm{I}-{ }^{\mathrm{k}} \mathrm{A}\right]^{-\mathrm{l}}$ is the Leontief Inverse of $\left[\mathrm{k}_{\mathrm{X}}\right]$ for all time periods, so that,

$$
\left[\mathrm{I}-{ }^{\mathrm{k}} \mathrm{A}\right]^{-1}\left[{ }^{\mathrm{k}} \mathrm{Y}_{\mathrm{t}}\right]=\left[{ }^{\mathrm{k}} \mathrm{Z}_{\mathrm{t}}\right]
$$

where $\left[{ }^{k} Y_{t}\right] \begin{aligned} & \text { is an } n \times l \text { vector of deliveries to final demand by the } k^{\text {th }} \\ & \text { region in period } t \text {, and }\end{aligned}$ 


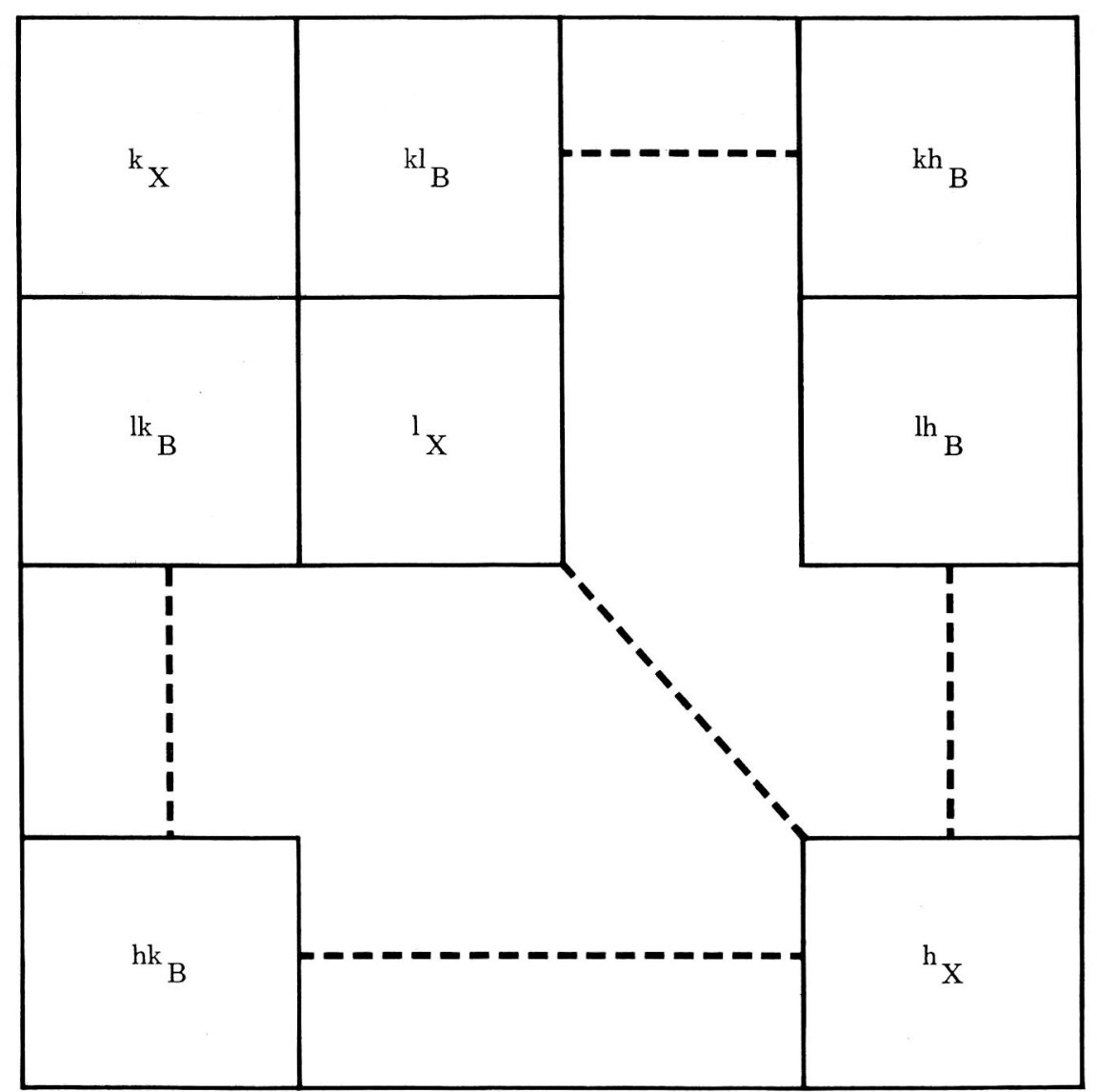

Figure 2. Schematic representation of a multi-region interregional input-output model

$\left[\mathrm{k}_{\mathrm{Z}}\right]$ is an $\mathrm{n} \times \mathrm{l}$ vector of total outputs by the $\mathrm{k}^{\text {th }}$ region in period $\mathrm{t}$. The basic relationship defined in Equation 1 holds for all regions.

Similarly, we define:

$$
\mathrm{k}_{\mathrm{it}} \in\left\{\left[{ }^{\mathrm{k}} \mathrm{Y}_{\mathrm{t}}\right]\right\}
$$

which holds for all regions.

We also assume a matrix of petroleum products requirements $[\mathrm{P}]$ of order $\mathrm{m} \times \mathrm{n}$ which is identical for all regions and all time periods.

That is:

$$
\mathrm{p}_{\text {id }} \epsilon\{[\mathrm{P}]\}
$$

and $p_{i d}$ is the direct requirement of the $d^{\text {th }}$ petroleum product needed by the $\mathrm{i}^{\text {th }}$ sector to produce one unit of total output. 
Hence:

$$
[\mathrm{P}]\left[\mathrm{I}-{ }^{\mathrm{l}, \mathrm{k}} \mathrm{A}\right]^{-\mathrm{l}}=\left[{ }^{\mathrm{l}, \mathrm{k}} \mathrm{R}\right]
$$

where $[1, \mathrm{k} R]$ is a matrix of order $\mathrm{m} \times \mathrm{n}$ of petroleum products required directly and indirectly to support delivery of one unit of output to final demand by the $1^{\text {th }}$ or $\mathrm{k}^{\text {th }}$ region,

and: $\quad{ }^{1, \mathrm{k}} \mathrm{r}_{\text {id }} \quad \in \quad\left\{\left[1, \mathrm{k}_{\mathrm{R}}\right]\right\}$

We further introduce a matrix $[\mathrm{l}, \mathrm{k} \mathrm{E}]$ of the order $\mathrm{g} \times \mathrm{n}$ of direct regional economic impacts associated with one unit of output by each sector in the economy of region $\mathrm{l}$ or $\mathrm{k}$, in all time periods and define:

$$
{ }^{1, k} \mathbf{e}_{\mathrm{ib}} \in\{[1, \mathrm{k} \mathrm{E}]\}
$$

where ${ }^{l, k} e_{i b}$ is the level of the $b^{\text {th }}$ economic impact directly associated with one unit of total output by the $i^{\text {th }}$ sector in the economy of the $\mathrm{l}^{\text {th }}$ or $\mathrm{k}^{\text {th }}$ region.

Hence:

$$
\left[{ }^{1, \mathrm{k}} \mathrm{E}\right]\left[\mathrm{I}-{ }^{\mathrm{l}, \mathrm{k}_{\mathrm{A}}}\right]^{-\mathrm{l}}=\left[{ }^{1, \mathrm{k}_{\mathrm{S}}}\right]
$$

where $\left[{ }^{1, k} \mathrm{~S}\right]$ is a matrix of order $\mathrm{g} \times \mathrm{n}$ of economic impacts directly and indirectly associated with delivery of one unit of output to final demand by the $\mathrm{l}^{\text {th }}$ or $\mathrm{k}^{\text {th }}$ region,

and: $\quad{ }^{1, k} \mathrm{~s}_{\mathrm{ib}} \in\{[1, \mathrm{k} \mathrm{S}]\}$

We return now to the interregional trade flow sub-matrices, $\left[{ }^{1 \mathrm{k}} \mathrm{B}_{\mathrm{t}}\right]$ and $[1$ $\left.{ }^{\mathrm{kl}} \mathrm{B}_{\mathrm{t}}\right]$, defined earlier. Let us assume that:

$(4)$

$$
\sum_{\mathrm{l}}^{\mathrm{h}-\mathrm{l}} \quad{ }^{\mathrm{k}} \mathrm{b}_{\mathrm{ijt}}=\quad{ }^{\mathrm{k}} \tau_{\mathrm{ijt}}
$$


where $\quad{ }^{\mathrm{k}} \tau_{\text {ijt }} \quad$ is the exact amount of the $\mathrm{j}^{\text {th }}$ input needed to be imported into region $\mathrm{k}$ to support ${ }^{\mathrm{k}} \mathrm{Z}_{\mathrm{it}}$ output,

and that the basic relationship defined in Equation 4 holds for all regions.

Then:

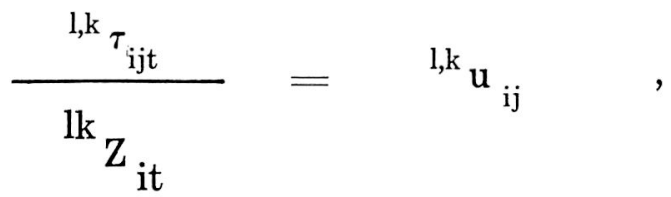

where ${ }^{l, k} u_{i j}$ is a coefficient of the amount of the $j^{\text {th }}$ imported input needed directly for the $\mathrm{i}^{\text {th }}$ sector of the $\mathrm{l}^{\text {th }}$ or $\mathrm{k}^{\text {th }}$ region to support one unit of output in all time periods in which technology is constant. We then define a matrix $\left[{ }^{1, k} U\right]$ of the order $n \times n$ of which ${ }^{l, k} u_{i j}$ is an element, and:

$$
\left[{ }^{1, \mathrm{k}_{\mathrm{U}}}\right]\left[\mathrm{I}-{ }^{\mathrm{l}, \mathrm{k}} \mathrm{A}\right]^{-\mathrm{l}}=\left[{ }^{1, \mathrm{k}} \mathrm{Q}\right]
$$

where $\left[{ }^{l, k} \mathrm{Q}\right]$ is a matrix of the order $\mathrm{n} \mathrm{x} \mathrm{n}$ of imports directly and indirectly required to support delivery of one unit of output to final demand in the $\mathrm{l}^{\text {th }}$ or $\mathrm{k}^{\text {th }}$ region,

and ${ }^{1, k} q_{i j} \in\left\{\left[l, k_{Q}\right]\right\}$

We can now define some identities which are useful in structuring our model. From Equation 2, it follows that:

\left. (7) ${\underset{\mathrm{i}}{\mathrm{n}}(}_{{ }^{1, \mathrm{k}} \mathrm{r}_{\mathrm{id}}}{ }^{\mathrm{l}, \mathrm{k}} \mathrm{Y}_{\mathrm{it}}\right)=\quad{ }^{\mathrm{l}, \mathrm{k}} \Psi_{\mathrm{dt}}$, for all $\mathrm{d}$,

where $\quad{ }^{l, k} \Psi_{d t} \quad$ is the total quantity of the $d^{\text {th }}$ petroleum product reguired in the $\mathrm{l}^{\text {th }}$ or $\mathrm{k}^{\text {th }}$ region in period $\mathrm{t}$. 
From Equation 3, it follows that:

(8) ${\underset{\Sigma}{\mathrm{i}}}_{\mathrm{n}^{\mathrm{n}}}\left({ }^{\mathrm{l}, \mathrm{k}} \mathrm{s}_{\mathrm{ib}}{ }^{\mathrm{l}, \mathrm{k}} \mathrm{y}_{\mathrm{it}}\right)={ }^{1, \mathrm{k}} \Upsilon_{\mathrm{bt}}$, for all $\mathrm{b}$,

where ${ }^{1, k} \Upsilon_{b t}$ is the total level of the $b^{\text {th }}$ import in the $l^{\text {th }}$ or $k^{\text {th }}$ region in period $t$,

and from Equation 6, it follows that:

(9) ${ }^{\mathrm{l}, \mathrm{k}} \mathrm{q}_{\mathrm{ij}}{ }^{\mathrm{l}, \mathrm{k}} \mathrm{y}_{\mathrm{it}}={ }^{\mathrm{l}, \mathrm{k}} \mathrm{K}_{\mathrm{ij}}$, for all $\mathrm{i}$ and all $\mathrm{j}$,

where ${ }^{1, k}{ }_{i j} \quad$ is the total quantity of the $j^{\text {th }}$ imported input needed by the $\mathrm{i}^{\text {th }}$ sector in the $\mathrm{l}^{\text {th }}$ or $\mathrm{k}^{\text {th }}$ region in period $\mathrm{t}$.

We define the quantity of imported inputs available to any region $\mathrm{l}$ or $\mathrm{k}$ as a matrix $[1, \mathrm{k} W]$ of the order $\mathrm{n} \times \mathrm{n}$, where:

$$
{ }^{1, \mathrm{k}} \mathrm{w}_{\mathrm{ij}} \in[\mathrm{l}, \mathrm{k} \mathrm{W}]
$$

and

$$
{ }^{\mathrm{k}} \mathrm{w}_{\mathrm{ijt}}=\stackrel{\mathrm{h}}{\mathrm{h}} \mathrm{l}^{\mathrm{l}, \mathrm{k}} \mathrm{b}_{\mathrm{ijt-l}}
$$

That is, the quantity of any $\mathrm{j}^{\text {th }}$ imported input available to the $\mathrm{i}^{\text {th }}$ sector in period $t$ is equal to the total flow of the $j^{\text {th }}$ input to the $i^{\text {th }}$ sector in the $k^{\text {th }}$ region in the previous period, and this relationship is assumed to hold for all regions.

\section{Initial Model: Sub-model}

The initial component of the model is a straightforward, single-region linear programming sub-model much as might be appropriate to optimizing petroleum allocations in the short-run. The sub-model involves maximization of an objec- 
tive function associated with the $\mathrm{b}^{\text {th }}$ economic impact, subject to constraints imposed by availability of petroleum stocks and by existing plant capacities of each sector. No account is taken of limitations on imported non-petroleum inputs since existing inventories are assumed to be adequate for production in this initial phase of the embargo. Hence, the sub-model is of the form:

(11) Maximize:

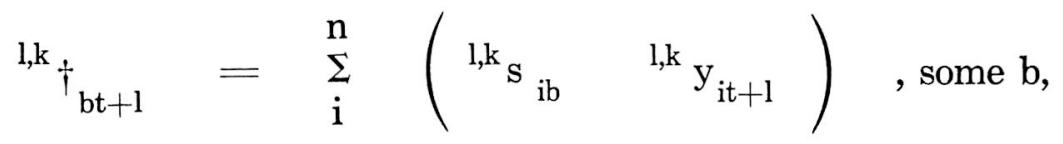

subject to:

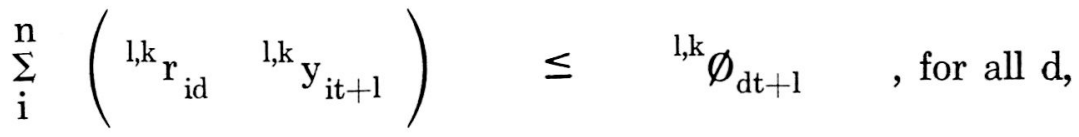

and:

(13) ${ }^{\mathrm{l}, \mathrm{k}} \mathrm{y}_{\mathrm{it}+\mathrm{l}} \leq{ }^{1, \mathrm{k}} \mathrm{C}_{\mathrm{it}+\mathrm{l}}$, for all $\mathrm{i}$,

where ${ }^{l, k} \emptyset_{d t} \quad$ is the available total stock of the $d^{\text {th }}$ petroleum product available in the $\mathrm{l}^{\text {th }}$ or $\mathrm{k}^{\text {th }}$ region in period $\mathrm{t}+\mathrm{l}$, and

${ }^{\mathrm{l}, \mathrm{k}} \mathrm{C}_{\mathrm{it}} \quad$ is the existing plant capacities of the $\mathrm{i}^{\text {th }}$ sector in the $1^{\text {th }}$ or $\mathrm{k}^{\text {th }}$ region in period $\mathrm{t}+\mathrm{l}$.

The initial sub-model is then solved for ${ }^{1, k} y_{i t+l}$, for all $i$ and regions $l$ and $\mathrm{k}$, and the solution vector fed back into Equation 1. That is:

$$
\left[\mathrm{I}-{ }^{1, \mathrm{k}_{\mathrm{A}}}\right]^{-\mathrm{l}} \quad\left[{ }^{1, \mathrm{k}_{\mathrm{Y}}} \mathrm{t+l}\right]=\left[{ }^{\mathrm{l}, \mathrm{k}_{\mathrm{Z}}}{ }_{\mathrm{t}+\mathrm{l}}\right]
$$

and then using the $\left[{ }^{1, k} \mathrm{P}\right]$ matrix:

$$
\sum_{\mathrm{i}}^{\mathrm{n}}\left({ }^{\mathrm{l}, \mathrm{k}} \mathrm{p}_{\text {id }}{ }^{\mathrm{l}, \mathrm{k}} \mathrm{Z}_{\mathrm{it}+\mathrm{l}}\right)={ }^{\mathrm{l}, \mathrm{k}} \mathrm{f}_{\text {idt }+\mathrm{l}}
$$

where $\quad{ }^{1, k} f_{i d t+l} \quad$ is the optimum allocation of the $d^{\text {th }}$ petroleum product to the $\mathrm{i}^{\text {th }}$ sector in the $\mathrm{l}^{\text {th }}$ or $\mathrm{k}^{\text {th }}$ region in period $\mathrm{t}+\mathrm{l}$ (the initial period of embargo). 
This initial sub-model also produces a set of interregional trade flow submatrices whose elements are ${ }^{1, k} b_{i j t+1}$ or ${ }^{k, l} b_{i j t+1}$ which must be accounted for in the second phase of the model as it is structured for period $t+2$.

\section{Regional Sub-model}

The period two sub-model is the first to encounter the intermediate-run problem of sub-optimization introduced earlier. In this period, imported inputs become potential constraints on production and must be given explicit attention. Hence, we must replace the set of constraints represented by Equation 13 in the initial sub-model by a set of constraints based on the relationship defined in Equations 9 and 10.

The period two sub-model for any region $\mathrm{l}$ or $\mathrm{k}$ becomes:

$$
\text { Maximize } \quad{ }^{\mathrm{l}, \mathrm{k}} \uparrow_{\mathrm{bt}+2}=\sum_{\mathrm{i}}^{\mathrm{n}}\left({ }^{{ }^{1, k} \mathrm{~s}_{\mathrm{ib}}}{ }^{1, \mathrm{k}} \mathrm{y}_{\mathrm{it}+2}\right) \text {, some b, subject to: . }
$$

$$
\sum_{\mathrm{i}}^{\mathrm{n}}\left({ }^{\mathrm{l}, \mathrm{k}} \mathrm{r}_{\mathrm{id}} \quad{ }^{\mathrm{l}, \mathrm{k}} \mathrm{y}_{\mathrm{it}+2}\right) \leq{ }^{\mathrm{l}, \mathrm{k}} \emptyset_{\mathrm{dt}+2} \quad \text {, for all } \mathrm{d},
$$

and:

$$
\mathrm{q}_{\mathrm{ij}}{ }^{\mathrm{l}, \mathrm{k}} \mathrm{y}_{\mathrm{it}+2} \leq{ }^{\mathrm{l}, \mathrm{k}} \Lambda_{\mathrm{ijt}+2} \text {, for all } \mathrm{i} \text { and all } \mathrm{j} \text {, }
$$

where $\quad{ }^{\mathrm{l}, \mathrm{k}} \Lambda_{\mathrm{ijt}+2}$ is the total quantity of the $\mathrm{j}^{\text {th }}$ imported input available to the $\mathrm{i}^{\text {th }}$ sector in the $\mathrm{l}^{\text {th }}$ or $\mathrm{k}^{\text {th }}$ region in period $\mathrm{t}+2$,

and:

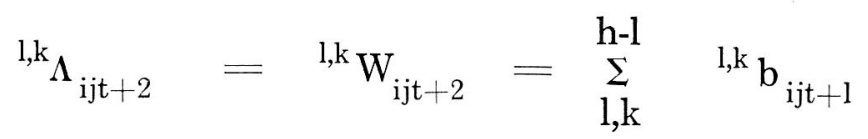

Although it is not imperative to do so, for the sake of convenience we will assume that:

$$
{ }^{\mathrm{l}, \mathrm{k}} \emptyset_{\mathrm{dt}+2}={ }^{\mathrm{l}, \mathrm{k}} \emptyset_{\mathrm{dt}+\mathrm{l}}
$$

This period two sub-model is also solved for the vector whose elements are ${ }^{l, k} y_{i t+2}$ for all regions $\mathrm{l}$ and $\mathrm{k}$, and that vector is substituted back into Equation 1 to obtain optimum sectorial petroleum allocations as demonstrated in Equations 14 and 15 of the initial period sub-model.

More importantly, perhaps, this period-two sub-model creates a potential situation in which some, or all, of the petroleum product stocks will not be exhausted. 
The dual of the sub-model will provide information on shadow prices, or marginal value products, of the petroleum resources. If a resource (i.e., either a petroleum or a non-petroleum input) is a limiting factor, it will have a shadow price greater than zero. On the other hand, any resource not being fully utilized will have a shadow price of zero. The shadow prices tell us how much additional $b^{\text {th }}$ economic impact we could generate if we had one more unit of the resource. Hence, a zero shadow price implies that the remaining, unused portion of the resource has zero value to the $1^{\text {th }}$ or $\mathrm{k}^{\text {th }}$ regional economy (given the objective function of the $1^{\text {th }}$ or $\mathrm{k}^{\text {th }}$ region). The same resource may have a shadow price greater than zero in some other region however. Thus, an interregional transfer of the resource could be made without loss of any opportunity in the region from which the transfer was made and with a gain to the region to which the resource was transferred. We take advantage of the concept of shadow prices in structuring the second-stage sub-model.

\section{Second-stage Sub-model}

The second-stage sub-model is a total economy sub-model designed to reallocate petroleum stocks between regions based on shadow price information generated by the period-two regional sub-model. Its rationale rests on the following relationships:

If,

$$
{ }^{1} \alpha_{\mathrm{dt}+2}=0, \text { some d, }
$$

where ${ }^{1} \alpha_{\mathrm{dt}+2}$ is the shadow price of the $\mathrm{d}^{\text {th }}$ petroleum product in the $\mathrm{l}^{\text {th }}$ region in period $t+2$,

then it follows that:

$$
{ }^{1} \emptyset_{\mathrm{dt}+2}-\left(\begin{array}{cc}
{ }^{1} \mathrm{r}_{\mathrm{id}} & { }^{1} \mathrm{y}_{\mathrm{it}+2}
\end{array}\right)=\quad{ }^{1} \Gamma_{\mathrm{dt}+2} \quad>0
$$

where ${ }^{1} \Gamma_{d t+2}$ is the quantity of surplus stock of the $d^{\text {th }}$ petroleum product in the $1^{\text {th }}$ region in period $t+2$.

On the other hand, if, 


$$
{ }^{\mathrm{k}} \boldsymbol{\alpha}_{\mathrm{dt}+2}>0, \text { some d, }
$$

then:

$$
{ }^{\mathrm{k}} \emptyset_{\mathrm{dt}+2}-\left({ }^{\mathrm{k}} \mathrm{r}_{\mathrm{id}}{ }^{\mathrm{k}} \mathrm{y}_{\mathrm{it}+2}\right)={ }^{\mathrm{k}} \Gamma_{\mathrm{dt}+2}=0 .
$$

Hence, a better solution can be had in period $t+3$ by assuring that:

$$
{ }^{1} \emptyset_{\mathrm{dt}+3}<{ }^{1} \emptyset_{\mathrm{dt}+2} \quad \text { and } \quad{ }^{\mathrm{k}} \emptyset_{\mathrm{dt}+3}>{ }^{\mathrm{k}} \emptyset_{\mathrm{dt}+2}
$$

For convenience, we will assume that the total stock of each petroleum product available in the entire economy in period $t+3$ is equal to that available in period $t+2$, so that:

$$
\sum_{1}{ }^{1} \emptyset_{\mathrm{dt}+2}+\sum_{\mathrm{k}}{ }^{\mathrm{k}} \emptyset_{\mathrm{dt}+2}=\sum_{1}{ }^{1} \emptyset_{\mathrm{dt}+3}+\sum_{\mathrm{k}} \phi_{\mathrm{dt}+3,} \text { for all d, }
$$

and that:

$$
{ }^{1} \emptyset_{\mathrm{dt}+3} \geq{ }^{1} \emptyset_{\mathrm{dt}+2}-{ }^{1} \Gamma_{\mathrm{dt}+2}
$$

Hence, the total interregional transfer is limited by:

$$
\sum_{\mathrm{k}}{ }^{\mathrm{k}} \mathrm{p}_{\mathrm{dt}+3} \leq \sum_{1}{ }^{1} \Gamma_{\mathrm{dt}+2}
$$

where ${ }^{k} p_{d t+3}$ is the quantity of the $d^{\text {th }}$ petroleum product transferred to the and:

$$
{ }^{\mathrm{k}} \phi_{\mathrm{dt}+3}={ }^{\mathrm{k}} \emptyset_{\mathrm{dt}+2}+{ }^{\mathrm{k}} \mathrm{p}_{\mathrm{dt}+3}
$$

There is a technical problem which arises here and must be addressed. The shadow prices generated by the period two sub-model tell us the MVP of one additional unit of the $d^{\text {th }}$ petroleum product in the $\mathrm{k}^{\text {th }}$ region, but they do not assure us that the second additional unit provided the $\mathrm{k}^{\text {th }}$ region would have the same value. Hence, it is possible to "overshoot" in the reallocation and some further constraint must be introduced to dampen oscillations which "overshooting" might introduce into the model. We, therefore, introduce an arbitrary governor on the interregional transfers to assure that only small, incremental changes are made on any given iteration of the model. That is:

$$
{ }^{\mathrm{k}} \mathrm{p}_{\mathrm{dt}+3}=\sigma_{\mathrm{dt}} \quad{ }^{\mathrm{k}} \emptyset_{\mathrm{dt}+2}
$$


where ${ }^{k} \sigma_{d}$ is the governor on incremental transfers of the $d^{\text {th }}$ petroleum product and is constant over all regions and all time periods.

Our second-stage sub-model then becomes:

(30) Maximize $\quad \Upsilon_{\mathrm{ot}+3}=\sum_{\mathrm{d}}^{\mathrm{m}} \sum_{\mathrm{k}}\left(\begin{array}{llll}{ }^{\mathrm{k}} \delta_{\mathrm{dbo}} & { }^{\mathrm{k}} \alpha_{\mathrm{dt}+2} & { }^{\mathrm{k}} \mathrm{p}_{\mathrm{dt}+3}\end{array}\right)$

subject to:

$$
\sum_{\mathrm{k}}{ }^{\mathrm{k}} \mathrm{p}_{\mathrm{dt}+3} \leq \sum_{1}{ }^{1} \Gamma_{\mathrm{dt}+2} \quad \text { for all } \mathrm{d},
$$

and

(32) $\left(\frac{1}{\sigma_{\mathrm{d}}}\right)\left({ }^{\mathrm{k}} \mathrm{p}_{\mathrm{dt}+3}\right) \leq{ }^{\mathrm{k}} \emptyset_{\mathrm{dt}+2}$, for all $\mathrm{d}$ and all $\mathrm{k}$,

where ${ }^{\mathrm{k}} \delta_{\mathrm{dbo}}$ is a factor which transforms a shadow price for the $\mathrm{d}^{\text {th }}$ petroleum product expressed in terms of the $\mathrm{b}^{\text {th }}$ impact in the $\mathrm{k}^{\text {th }}$ region into the $\mathrm{o}^{\text {th }}$ national impact units.

This second-stage sub-model is then solved for ${ }^{k} p_{d t+3}$ and new regional allocations are determined for period $t+3$. By Equation 28, we can obtain allocations for all regions k. For all regions 1 we pro-rate any residual product over and above $\sum_{\mathrm{k}}{ }^{\mathrm{k}} \phi_{\mathrm{dt}+3}+\sum_{1}{ }^{1} \emptyset_{\mathrm{dt}+2} \quad$ That is:

(33) $\underset{1, \mathrm{k}}{\mathrm{h}}{ }^{1, \mathrm{k}} \emptyset_{\mathrm{dt}+2}-\left(\sum_{\mathrm{k}}{ }^{\mathrm{k}} \emptyset_{\mathrm{dt}+3}+\sum_{1}{ }^{1} \emptyset_{\mathrm{dt}+2}\right)=\Pi_{\mathrm{dt}+3}$ and

$$
\frac{\Pi_{\mathrm{dt}+3}}{\sum_{1}{ }^{1} \phi_{\mathrm{dt}+2}}=\int_{\mathrm{dt}+3}
$$

where $\Pi_{d t+3}$ is the residual of the $d^{\text {th }}$ petroleum product remaining in period $t+$ 3 after reallocation to all regions $\mathrm{k}$ and supplying all regions 1 with the $t+2$ allocation, and

$\int_{d t+3}$ is the fraction represented by the residual of the $d^{\text {th }}$ petroleum product of the total $t+2$ allocations to all regions 1 ,

so that:

$$
{ }^{1} \emptyset_{\mathrm{dt}+3}=\left(1.0+{ }_{\mathrm{dt}+3}\right) \quad{ }^{1} \emptyset_{\mathrm{dt}+2}
$$




\section{Iterating the Model}

The basic components of the two-stage model to be iterated are the regional sub-model and the second-stage sub-model. But before the iteration process can go beyond period $t+2$, we must take steps to avoid falling into an imported inputs trap. That is, since the imported inputs available in period $t+3$ must have been produced in some previous time period, and since petroleum and nonpetroleum inputs must be used in fixed proportions, it is possible that sectors receiving additional petroleum allocation in $t+3$ may not be able to utilize that increased allocation in that time period because of a shortage of non-petroleum inputs indirectly attributable to petroleum shortages in previous periods. To avoid this trap, we will assume that:

$$
{ }^{1, \mathrm{k}} \Lambda_{\mathrm{ijt}+3}={ }^{1, \mathrm{k}} \mathrm{w}_{\mathrm{ijt}+3}=\sum_{1, \mathrm{k}}^{\mathrm{h}-1}{ }_{\mathrm{l}, \mathrm{k}} \mathrm{b}_{\mathrm{ijt}+2}+{ }^{1, \mathrm{k}} \Omega_{\mathrm{ijt}+2}
$$

where:

$$
{ }^{1, \mathrm{k}} \Omega_{\mathrm{itj}+2}={ }^{1, \mathrm{k}} \Lambda_{\mathrm{ijt}+2}-\left({ }^{1, \mathrm{k}} \mathrm{q}_{\mathrm{ij}}{ }^{1, \mathrm{k}} \mathrm{y}_{\mathrm{it}+1}\right)
$$

That is, where ${ }^{1, \mathrm{k}} \Omega_{\mathrm{ijt}+2}$ is surplus quantities of the $\mathrm{j}^{\text {th }}$ imported input for the $\mathrm{i}^{\text {th }}$ sector in the $1^{\text {th }}$ or $\mathrm{k}^{\text {th }}$ region held over from period $\mathrm{t}+2$, then the constraints imposed on the regional sub-model are adjusted in each iteration both for interregional transfers of petroleum allocations as indicated by the second-stage sub-model and for changes in levels of non-petroluem inputs due to production in the previous run of the regional sub-model and carry-overs. For example, the third period regional sub-model takes the form:

(38) Maximize

$$
{ }^{1, \mathrm{k}_{\dagger}}{ }_{\mathrm{bt}+3}={\underset{\mathrm{i}}{\mathrm{n}}}^{\mathrm{n}}\left({ }^{1, \mathrm{k}} \mathrm{s}_{\mathrm{ib}}{ }^{1, \mathrm{k}} \mathrm{y}_{\mathrm{it}+3}\right) \text {, for all } 1 \text { and all } \mathrm{k}
$$

subject to:

$$
\sum_{\mathrm{i}}^{\mathrm{n}}\left({ }^{1, \mathrm{k}} \mathrm{r}_{\mathrm{id}}{ }^{1, \mathrm{k}} \mathrm{y}_{\mathrm{it}+3}\right) \leq{ }^{1, \mathrm{k}} \phi_{\mathrm{dt}+3} \quad, \text { for all } \mathrm{d},
$$

and ${ }^{1, k} q_{i j} \quad{ }^{1, k} y_{i t+3} \leq{ }^{1, k} \Lambda_{i j t+3} \quad$, for all $\mathrm{i}$ and all $\mathrm{j}$.

New shadow prices are computed, the second-stage sub-model is reiterated to determine regional petroleum allocations for period $t+4$, and so on. The process is continued for a number of iterations until:

$$
{ }^{1, \mathrm{k}}{ }_{\mathrm{bt}+\mu} \geq 1, \mathrm{~K}_{\mathrm{bt}+(\mu-1)} \geq{ }^{1, \mathrm{k}} \Gamma_{\mathrm{bt}+(\mu+1)} \text {, all } 1 \text { and all } \mathrm{k} \text {, }
$$

in which case ${ }^{1, \mathrm{k}} \rho_{\mathrm{bt}+\mu}$ represents the best solution obtainable. A schematic flow-chart of the iterative process is presented in Figure 3.

It might be noted that: 


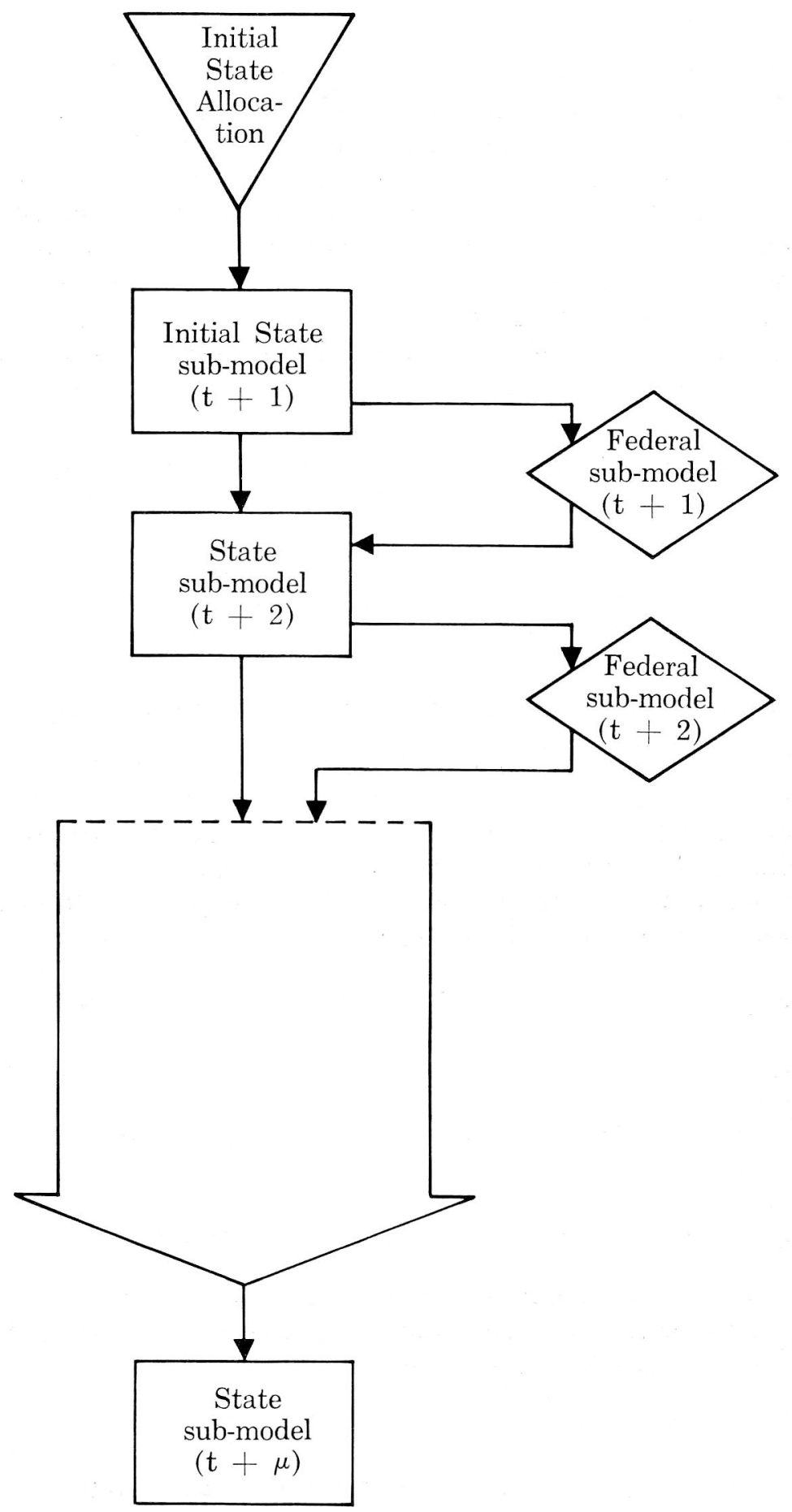

Figure 3. Schematic flow-chart of iterative process 
(41)

$$
\mu=\mathrm{f}(\sigma)
$$

and that:

(42) $\lim \mu=\infty$

Hence, the larger the governor, $\sigma$, the fewer iterations needed but also, the smaller $\sigma$, the closer the $\mu^{\text {th }}$ iteration will approximate a global optimum solution.

\section{Summary and Concluding Comments}

This paper has presented a two-stage, heuristic model designed to deal with intermediate-run problems arising from severe shortages of petroleum products. The main theme of the paper is that the shortage of petroleum products may disrupt interindustry trade flows on both an intraregional and interregional basis so as to effectively prevent any single region from establishing an effective petroleum allocation policy. Thus a "feedback" mechanism is built into the model to prevent some petroleum allocations from going unused due to limiting non-petroleum inputs caused by petroleum shortages experienced elsewhere in previous production periods. By incorporating appropriate assumptions about the length of production lags, the model can be run as a simulation model in advance of any actual petroleum shortage, thus, predicting areas in which problems are likely to occur. This would allow time for the interregional allocation decisions, on which successful state allocation programs must be predicated, to be made at the federal level.

Policy implications to be drawn from the model presented here are clear. First, the interregional nature of the problem will require allocation decisions at both state and federal levels, and the minimization of economic disruption would require that interregional decisions at the federal level be made in advance of any severe petroleum shortage. These decisions would then provide information on which state officials could base rational allocation programs. Thus, the main policy emphasis should be on providing modeling capabilities at both the federal and state levels. Especially important in this regard is the existence of a usable interregional input-output model of the U.S. economy, since such a model is the basis of coefficients used in implementing a linear programming approach such as the one presented in this paper. Again, it should be stressed that the policy implications from the model presented here are threefold. These are: 1) The problem of petroleum allocation is interregional in nature and requires policy decisions at both state and federal levels. 2) Rational decisions at both levels of government regarding allocation programs require modeling procedures. which do not currently exist. 3) The existence of time lags in production processes requires allccation priorities to be established prior to any actual shortage of petroleum. In short, failure to develop contingency plans could result in economic disruptions which are much more severe than necessary if petroleum shortages actually occur.

The model presented in this paper must be viewed with an eye to its limitations. The model incorporates the linearity and fixed technology assumptions 
underlying input-output analysis and linear programming models. Over the short and intermediate-run, with which the model is concerned, drastic technological changes are not likely to occur; however, the linearity assumptions which require the use of inputs in fixed proportions could bias the results of the analysis. To the extent that inputs can be substituted for each other, the model may tend to overstate the severity of input shortages. However, even with its limitations, the model provides an economically feasible means for establishing rational petroleum allocation policies while preserving traditional relationships between the state and federal levels of government.

\section{REFERENCES}

1. Carter, Anne P., "Applications of Input-Output Analysis to Energy Problems," Science, 104 (19 April 1974), pp. 325-329.

2. Harris, Britton, "Heuristics and Design," Papers of the Regional Science Association, 31 (Twelfth European Congress, Rotterdam, 1972), pp. 3-13.

3. Helms, Robert B., Natural Gas Regulation, Washington, D.C., American Enterprise Institute, 1974.

4. Lipsey, R. G., and K. Lancaster, "The General Theory of the Second Best," The Review of Economic Studies, Vol. XXIV, No. 63, pp. 11-32.

5. Miller, Roger LeRoy, The Economics of Energy, San Diego, Morrow Publishers, 1974.

6. Morgenstern, Oskar, Klaus P. Heiss, and Klaus Knorr, Long Term Projections of Power, Cambridge, Ballinger Publishing Company, 1974.

7. Mulkey, David, and James C. Hite, “An Input-Output Analysis of Energy Use by South Carolina Agriculture," paper presented at meetings of American Agricultural Economics Association, Texas A\&M University, College Station, August 20, 1974.

8. Polenske, Karen R., "Empirical Inplementation of a Multi-Regional Input-Output Gravity Trade Model," Contributions to Input-Output Analysis, A. P. Carter and A. Brody, editors, Amsterdam: North-Holland Publishing Company, 1970. 